\title{
On the radiometer
}

\section{Dr.J. Puluj}

To cite this article: Dr. J. Puluj (1879) On the radiometer, Philosophical Magazine Series 5, 8:48, 259-260, DOI: $10.1080 / 14786447908639682$

To link to this article: http://dx.doi.org/10.1080/14786447908639682

$$
\text { 曲 Published online: } 13 \text { May } 2009 .
$$

Submit your article to this journal 전

LII Article views: 3

Q View related articles ¿ 


\section{Intelligence and Miscellaneous Articles.}

directly, by menns of a spring dynamometer, the work required for the induction of an electric current of determined strength in a circuit of given resistance, and comparing it with that calculated from theory.

A magnetoelectrical machine for continuous currents served for the induction-apparatus, the electromotive force of which had previously been exactly ascertained and found to be proportional to the number of turns. The dynamometer was a dynamometric winch of the newest construction, provided with a markingapparatus for sketching the work-curves. Its scale was tested by direct loading, and found accurate. The dynamometric winch was screwed to the induction apparatus on an axle attached to the machinery instead of the ordinary winch.

For the measurement of the induced currents a tangent-compass, the reduction-factor of which was exactly ascertained, was inserted in the circuit, of which the resistance was measured as accurately as possible, and could be altered at pleasure by means of inserted scales. For counting the number of turns a seconds' pendulum with a lond stroke wis used.

Five experiments were made : in three the velocity of rotation amounted to 1 revolution of the winch in 1 second (corresponding to 7 revolutions of the inductor); in the two other experiments 1 turn of the winch took 2 and 4 seconds respectively. In each experiment 65 turns were executed-once with interrupted, and once with closed circuit. The difference between the work recorded by the dynamometer in the one case and in the other was the work of induction expended for the production of the current simultaneously measured on the tangent-compass according to the proportion of the electromotive force calculated from the number of turns or from the known resistance. It amounted, according to the very well accordant results of the five experiments, in which the expenditure of induction-work lay between the limits of $\frac{1}{3}$ and 6 meter-kilograms, to the electromotive force of one Daniell element, and to the resistance of one Siemens unit, reduced 0.13 metrekilogram per second-a result which comes very near theoretical determinations.

Comparing this value of the work with the number of calories corresponding to the chemical processes that take place in a Daniell series with equal resistance, we get for the mechanical equivalent of the heat, on using the numbers given by $W$. Thomson and Jenkin, the number 428 , or, if we take as the basis of the calculation the higher amount of induction-work in the first four experiments, the number 421 , very closely agreeing with the generally accepted equivalent of Joule.-Kaiserliche Akademie der Wissenschaften in Wien, mathematisch-natur'vissenschaftiche Classe, July 3 , 1879 .

ON THE RADTOMETER. BY DR. T. PULUJ.

The paper contains a criticism of the evaporation theory of Osborne Reynolds and the emission theory of Zollner. 
Were evaporation or the emission of molecules on the irradiated side of the vane the only or at least the chief cause of the radiometermotion, this would of necessity increase when the rarefaction is continued, since according to experience both evaporation and the emission of molecules must be so much the more vigorous tho lower the pressure in the space occupied by rarefied gas. But, as we have learned from experiments by Finkener and Crooks, the moment of rotation exerted by the flame upon the radiometer at first increases, cceteris paribus, with the rarefaction of the gases, reaches its maximum at a certain pressure, and with further rarefaction decreceses. 'Tbis diminution of the radiometric effect, which nua fall to $\frac{1}{10}$ of the maximum value, contradicts the abovementioned consequence of the theories of evaporation and emission. On the other hand, however, the hypothesis that all bodies, independently of their aggregate-condition, evaporate eveu at ordinary temperatures cannot be called in question; hence it must be admitted that a force of reaction will also result from the emission of molecules. But, in order to explain the above-mentioned diminution of the radiometric motion, it must be assumed, further, that the reaction-forces resulting from the emission must be either vanishingly small, or so small in comparison with the forces arising from the recoil of the molecules of the gaseous material still present that the motion-phenomena are either exclusively or chiefly conditioned by the latter forces.

On this hypothesis, that decrease of the motion can be explained, according to the kinetic theory of gases, in the following manner:-At the full atmospheric pressure the reaction-force called forth on the irradiated side of the vane is too little to overcome the resistance presented by friction and the air. At sufficient rarefaction the reaction-force overcomes those resistances, and the motion of the vane commences. If the reaction-force, like the internal friction, decreases only very slowly with the pressure, the velocity of the movement attains its maximum at a certain pressure, and decreases when the rarefaction is continued, because not merely the resistance of the air, but also the force of the reaction excited becomes less with the lessened number of the recoiling molecules. In a space absolutely void of air the motion must cease entirely, if no emission of molecules results on the irradiated side of the rane.

Further, the author describes a radiometer consisting of a fixed cross of mica lamella blackened on one side, and a very thin cylindrical glass case. The distance of the outermost edges of the vanes from the glass amounted to 2 millims. When light fell upon it the glass cylinder rotated in the opposite direction to that in which the cross would have been eaused to turn.

The object of this experiment is, to furnish a complete demonstration that the motious in the radiometer cannot be explained by means of currents of air.-Sitzung der mathematisch-naturwissenschaftichen Classe der kaisertichen Alaclemie der Wissenschaflen in Wien, July 3, 1879. 